decides whether a complaint should be dealt with by a formal procedure. As a result, general practitioners have faced time consuming and stressful investigations and hearings, even when the complaint concerned a trivial matter. Officers dealing with complaints in general practice have not been held accountable for deciding whether to go to a formal hearing in any particular case. Satisfying the complainant has been the object of complaints procedures in general practice, not necessarily ensuring that justice is being done.

General practitioners facing a complaint in the past have been found in breach of their terms of service in areas not covered by the complaint. The chief executive or, in primary care, a specially appointed complaints executive will therefore need not only to check that the issues are clearly stated and appropriate but to be held accountable for deciding whether a complaint should be rejected before stage II is initiated.

General practitioners are in a position to forewarn their NHS colleagues of the taste of things to come. Before accepting the proposals our leaders should seek clarification on the aforementioned points and, indeed, many others that general practitioners are anxious about.

Rosedale Surgery,

Cariton Colville,

Lowestoft, Suffolk NR33 8SH

1 Forsythe M. New NHS complaints procedure. $B M F$ 1994;308: 1315-6. (21 May.)

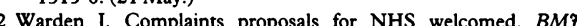
1994;308:1322. (21 May.)

3 O'Driscoll FA. Complaints review has failed. Monitor Weekly 1994;7(22):15.

4 Pietroni PC, de Uray-Rau S. Informal complaints procedure in general practice. $B M \mathcal{F} 1994 ; 308: 1546-8$. (11 June.)

5 Department of Health. Being heard. The report of a review committee on NHS complaints and procedures. London: $\mathrm{DoH}$ 1994.

\section{Pregnancy and immunity}

EDrTor,- The idea of a fetus acting as an allograft is fascinating.' The concept of localised complex signalling systems, with signals passing from the conceptus to the mother throughout pregnancy, is appealing and is given further credence by evidence that embryo derived suppressor factors may play a part in early implantation. ${ }^{2}$ Gordon $M$ Stirrat uses the absence of HLA antigens on the synctiotrophoblast to back up his statement that "immune adaptation is not required for the mother to cope with the fetus as an allograft."

The fetal-maternal allograft is often quoted as an immunological paradox. Several immunological features that arise during pregnancy are paradoxical to the editorial's main theme. For instance, there is clearly a modulation away from cell mediated immunity (a fact acknowledged in the editorial), which may entail suppression of interleukin-2. ${ }^{3}$ This immunomodulation results in the maternal serum becoming highly immunosuppressive during the second and, especially, the third trimesters of pregnancy.

Furthermore, research into recurrent spontaneous abortion also indirectly indicates that other maternal immune adaptations occur. Despite the absence of HLA antigens on the synctiotrophoblast, couples who share too many HLA antigens seem to be more prone to recurrent spontaneous abortion. ${ }^{4}$ Women suffering from recurrent spontaneous abortion seem to fail to make antibodies to their partner's lymphocyte antigens, ${ }^{4}$ although a clear mechanism explaining the need for antipaternal antibodies in maternal serum has not been established. ${ }^{4}$ Certain allergic conditions (my unpublished data) and certain immunological conditions, such as rheumatoid arthritis, ${ }^{5}$ improve considerably during pregnancy, which perhaps provides further evidence of a more generalised

immunosuppression arising from the modulation of cell mediated immunity.

Further research will almost certainly show that most mothers remain immunocompetent through out pregnancy, but the above mentioned paradoxes suggest that we are still viewing only the tip of the iceberg with regard to the complex immunology of pregnancy. More careful study of cancers arising de novo in pregnancy, the complications of certain cancers during pregnancy (breast cance and non-Hodgkin's lymphoma, for example), and other diseases (allergies, systemic lupus erythematosus, other autoimmune conditions) may throw more light on the matter. In particular, we need to recognise that, especially during the third trimester of pregnancy, some mothers may be appreciably immunosuppressed.

SAMMY LEE

Director

Andrology Clinic,

Hale Clinic,

London WIN 3HE

1 Stirrat GM. Pregnancy and immunity. BMf 1994;308:1385-6. (28 May.)

2 Daya S, Lee S, Underwood J. Mowbray JF, Craft IL, Clark DA Prediction of outcome following in vitro fertilized human embryos by measurement of embryo-derived suppressor factor. In: Clark DA, Croy BA, eds. Reproductive immunology. factor. In: Clark DA, Croy BA, eds.

3 Nicholas NS, Panayi GS, Nouri AME. Human pregnancy serum inhibits interleukin-2 production. Clin Exp Immunol 1984;58: $587-95$.

4 Underwood JL, Mowbray JF. The immunological approach to the treatment of human recurrent spontaneous abortion by immunization with lymphocytes. In: Chaouat G, ed. The immunology of the fetus. Florida: CRC Press, 1990:307-14.

5 Holland D, Bretscher P, Russell AS. Immunologic and inflammatory responses during pregnancy. F Clin Lab Immunol 1984;14:177-9.

\section{Safety and magnetic resonance imaging}

EDITOR,-Ivan Moseley gives a wide ranging review of the prostheses that may be adversely affected by magnetic resonance imaging.' ${ }^{1}$ To this should be added the prostheses that are used in otolaryngology. Hearing aids, particularly those "in the canal," are easily overlooked and may be damaged. Some grommets have a wire attachmen to aid their removal and are therefore theoretically at risk of displacement. Steel wire is also a component of some stapes prostheses, displacement of which may cause deafness, vertigo, and tinnitus. Other metallic objects that are occasionally used include clips to ligate branches of the maxillary artery and staples after excision of a pharyngeal pouch.

As patients may be unaware of the details of their surgical history, it may be prudent to consider issuing cards after surgery that provide information on the use of metallic objects or prostheses.

HAMID DAYA

Registrar NEIL WEIR

Department of Otolaryngology

Royal Surrey County Hospital,

Guildford GU2 5XX

1 Moseley I. Safety and magnetic resonance imaging. $B M$ 1994;308:1181. (7 May.)

\section{Pituitary tumours}

EDITOR,-Andrew Levy and Stafford L Lightman review the diagnosis and management of pituitary tumours. ${ }^{1}$ Our practice differs from theirs in one important aspect.

The authors suggest that if the circulating cortisol concentration increases to over $495 \mathrm{nmol} / \mathrm{l}$ in response to $250 \mu \mathrm{g}$ of tetracosactrin then glucocorticoid replacement is unnecessary. The use of the short tetracosactrin test as a substitute for the insulin tolerance test for postoperative assessment of the hypothalamic-pituitary-adrena axis remains controversial. Stewart et al have suggested that the short tetracosactrin test is generally sufficient and that the insulin tolerance test should be reserved for patients who yield an abnormal result in the short tetracosactrin test. ${ }^{2}$ We have reservations about this and reviewed the results of all paired short tetracosactrin and insulin tolerance tests performed in the past three years in our investigation unit. Among the 27 patients in whom the insulin tolerance test yielded an abnormal result the cortisol concentration was over $500 \mathrm{nmol} / 1$ at 30 minutes in four whereas it had reached this value at 60 minutes in 10 . If the criterion of a circulating cortisol concentration of $700 \mathrm{nmol} / \mathrm{l}$ at 30 minutes had been used no patients would have been missed, whereas if a cortisol concentration of $650 \mathrm{nmol} / 1$ had been used two patients would have been missed. The value at 30 minutes provides a better indication of the function of the hypothalamic-pituitary-adrenal axis. The short tetracosactrin test may be a safe, simple, cheap, and reasonably reliable substitute for the insulin tolerance test, but the cortisol concentration considered to represent a normal response remains undetermined. Registrar in endocrinology P KENDALL-TAYLOR Professor of endocrinology P H BAYLIS

Royal Victoria Infirmary, Newcastle upon Tyne NE1 4LP

1 Levy A, Lightman SL. Diagnosis and management of pituitary tumours. BMF 1994;308:1087-91. (23 April.)

2 Stewart PM, Corrie J, Seckl JR, Edwards CR, Padfield PL. A rational approach for assessing the hypothalamic-pituitaryadrenal axis. Lancet 1994;343:1208-10.

\section{Finns defined patients' rights before Dutch}

EdITOR,-A new, comprehensive law on patients' status and rights in Finland took effect on 1 March 1993 after a long period of preparation. Thus Finland was the first country in Europe, one year before the Netherlands, ${ }^{1}$ to pass a law defining the responsibilities of health professionals to their patients.

The Finnish Act on Status and Rights of Patients concerns the care and treatment of patients in all health care settings. The act thus covers municipal, private, and state health care. Every person who lives permanently in Finland is, without discrimination, entitled to the medical care required by his or her state of health within the limits of the resources that are available to health care at the time.

The aim of the new law is to secure patients' rights to health care of good quality and to self determination. The patient has a right to refuse a certain treatment or measure and to be cared for, as far as possible, in another medically acceptable way in mutual understanding. The act covers, among other things, access to treatment, patients' right to be informed, the right to self determination, the status of patients who are minors and the powers of a representative of the patient, emergency treatment, complaints and the patients' ombudsman, patients' documents, and confidentiality of information in patients' documents.

In addition to this act we have a law concerning injuries to patients, which took effect on 1 May 1987. It has created an insurance system, which compensates for personal injuries suffered in connection with health and medical care.

A bill concerning health care professionals and their practice, registration, and control is currently being considered by parliament. The aim has been to include all health care workers, be they medical, 
nursing, or other staff trained in health care, in the same law.

These reforms represent our way of modern thinking. We believe that Finland is the first country in Europe to include all health care professionals in the same law, in the same way as it was the first country to have a law defining patients' rights.

MARJA-LIISA PARTANEN Deputy director

TYYNE MARTIKAINEN Senior counsellor

Department for Social and Health Services,

Ministry of Social Affairs and Health in Finland,

PO Box 267,

PO Box 267,

Finland

1 Sheldon T. Dutch law defines patients' rights. $B M \mathcal{F} 1994 ; 308$ 616. (5 March.)

\section{Metal detectors to detect aluminium}

EDITOR,-D M Bradburn and colleagues highlight the poor radiodensity of aluminium. ${ }^{\prime}$ We now use a hand held portable metal detector (Adams Electronics, Edenbridge, Kent) to detect the presence of metal fragments in patients presenting to our accident and emergency department with a history of having ingested or inhaled metal frag ments. This metal detector is sensitive to al metals, particularly closed rings such as the ring pulls on aluminium cans.

In the light of Bradburn and colleagues' case report we tested the ability of our metal detector to detect a metallic tab placed over the neck of one of us. A strong signal was emitted when scanning was performed from the opposite side. We note that the patient reported on had attended two acciden and emergency departments and that radiographs obtained in both departments had not shown any abnormality. Had the patient been tested with a metal detector the presence of an aluminium fragment might have been detected earlier.

We propose that metal detectors should be used more widely in accident and emergency departments. They have provided information equivalent to that provided by plain radiographs in patients suspected of having ingested a foreign body ${ }^{2}$ and in one case in which a razor blade was located in the oesophagus.

JOHN RYAN Senior registrar in accident and emergency BRIAN TIDEY Royal Sussex County Hospital Brighton BN2 5BE

1 Bradburn DM, Carr HF, Renwick I. Radiographs and aluminium: a pitfall for the unwary. $B M \mathcal{F}$ 1994;308:1226. (7 May.)

2 Arena L, Baker SR. Use of a metal detector to identify ingested metallic foreign bodies. Am $\mathcal{F}$ Roentgenol 1990;155:803-4

3 Kessler A, Yellin A, Kessler A, Kronenberg J. Use of a metal detector in the location of a swallowed razor blade in the oesophagus. F Laryngol Otol 1990;104:435-6.

\section{Smoking in aeroplanes}

EDITOR,-Unfortunately, Richard Harding's editorial on the many factors related to health and comfort in passenger aircraft ${ }^{1}$ has been used by the tobacco industry to support its campaign, in the daily press in Hong Kong, against the nonsmoking flights recently introduced by Cathay Pacific and other airlines. ${ }^{1}$ The key paper quoted in the editorial, by Crawford and Holcomb, argues that environmental factors other than tobacco smoke may cause problems such as headaches and eye, nose, and throat symptoms. ${ }^{2}$ This is hardly the only issue related to environmental tobacco smoke in aircraft, but it is perhaps not surprising that the article made such claims, and readers may wish to consider the article's origins when assessing the evidence.

Both of the authors are well known as supporters of the tobacco industry in Australia and the United States. Larry Holcomb admits to being a consultant to the tobacco industry and has appeared regularly for it in the United States and other parts of the world. His advocacy for a relaxation of bans on smoking in aircraft has also been used by the industry in Denmark and Finland. In Hong Kong, in May 1992, he appeared as an "expert on environmental tobacco smoke" at a seminar held by the tobacco industry for the media, from which academic and other public health staff were excluded. Later, on a phone in programme on Radio Hong Kong, he attempted to refute the evidence for the effects of environmental tobacco smoke on the respiratory health of children.

A J HEDLEY

$$
\begin{aligned}
& \text { Department of Community Medicine } \\
& \text { and Unit for Behavioural Sciences, } \\
& \text { University of Hong Kong, }
\end{aligned}
$$$$
\text { Hong Kong }
$$

Head of department

1 Harding R. Cabin air quality in aircraft. $B M 7$ 1994;308:427-8. (12 February.)

2 Crawford WA, Holcomb LC. Environmental tobacco smoke (ETS) in airliners-a health hazard evaluation. Aviat Space Environ Med 1991;62:580-6.

\section{Falling sperm quality}

EDrToR,-Stephen Farrow comments on the quality of the evidence concerning a possible decline in sperm quality, ${ }^{1}$ focusing attention on our paper published in $1992 .{ }^{2}$ Farrow also responds to a paper by Peter Bromwich and colleagues, for which we provided the commentary.

Farrow questions our systematic search of the databases MEDLINE and Index Medicus. A necessary requirement for a valid overview, however, is that the criteria for including articles in the overview (and for excluding them) are explicit and reproducible to avoid selection bias. Several precautions were taken to avoid any undue influence of papers with small numbers of men in them. Firstly, the statistical analyses were weighted by the inverse of the sample size (not the logarithm of the sample size as Farrow claims). Secondly, we identified those studies that contributed most to the statistical association: most of these studies included large numbers of men. Replacing the date of publication by the date of data collection was feasible for only a limited number of publications, and the effect of relying on the publication date should not give rise to bias, only to a possible dilution of the effect.

We agree that the distribution of the data is obviously skewed and that use of the medians instead of the means would have been preferable. The information provided in the articles, however, did not allow for an analysis based only on the medians.

Farrow criticises our illustration of the decline in sperm concentration with a simple linear regression analysis. Indeed, the fit of this regression line is not very satisfactory, and before submitting the paper we performed several different analyses. The best fit among the more simple models was obtained by one sperm count before 1965, estimated as $110 \times 10 \% \mathrm{ml}$, and highly significantly different from another sperm count, estimated as $73 \times 10 \% \mathrm{ml}$, after 1965 . This fit is compatible with the suggestion that the decline may have stopped. On the other hand, interestingly, a recent study by Auger et al showed a clearly significant decline in sperm concentration in 1351 fertile donors examined at the same clinic in Paris between 1973 and $1992 .{ }^{4}$ Similarly, Von Waeleghem et al found a significant deterioration in sperm quality in 360 consecutive Belgian semen donors from 1977.5

In conclusion, on the basis of the admittedly fragile instrument of meta-analysis the evidence cannot lead us to a conclusion other than that sperm concentrations now are lower than they were in the 1940 s and ' $50 \mathrm{~s}$. This evidence needs to be combined with other types of evidence, but we do not believe that further statistical analysis will make any qualitative difference to the main message.

Our conclusion should perhaps be seen in the light of other aspects of semen quality in the general population: according to the World Health Organisation's classification, human semen is now considered to be normal even if up to $70 \%$ of the spermatozoa have abnormal morphologya percentage much higher than in most other mammals. ${ }^{6}$ Finally, there is no reason to doubt that the incidence of testicular cancer (a disease associated with low semen quality) is increasing considerably. ${ }^{7}$

\section{Statistical Research Unit, \\ University of Copenhagen, \\ Panun Institute, \\ DK-2200 Copenhagen \\ Denmark}

ALEKSANDER GIWERCMAN Senior registrar ELISABETH CARLSEN Research fellow NIELS E SKAKKEBAEK Professor

University Department of Growth and Reproduction,

Section GR-5064

Rigshospitalet,

DK-2100 Copenhagen

Denmark

1 Farrow S. Falling sperm quality: fact or fiction? $B M F 1994 ; 309$ 1-2. (2 July.)

2 Carlsen E, Giwercman A, Keiding N, Skakkebæk NE. Evidence for decreasing quality of semen during past 50 years. $B M \mathcal{J}$ 1992;305:609-13.

3 Bromwich P, Cohen J, Stewart I, Walker A. Decline in sperm counts: an artefact of changed range of normal? BMF 1994; 309:19-22.

4 Auger J, Czyglik F, Kunstmann JM, Jouannet P. Significant decrease of semen characteristics of fertile men from the Paris area during the last 20 years. Hum Reprod 1994;9(suppl 4):72. (Abstract.)

5 Van Waeleghem K, De Clercq N, Vermeulen L, Schoonjans F, Comhaire F. Deterioration of sperm quality in young Belgian men during recent decades. Hum Reprod 1994;9(suppl 4):73. (Abstract.)

6 Skakkebæk NE, Giwercman A, de Kretser D. Pathogenesis and management of male infertility. Lancet 1994;343:1473-9.

7 Moller $\mathrm{H}$. Clues to the aetiology of testicular germ cell tumour from descriptive epidemiology. Eur Urol 1993;23:8-16.

\section{Epidemic of asthma possibly related to thunderstorms}

Editor,-At 1300 on 25 June the National Poisons Unit was notified by Whipps Cross accident and emergency department that 55 people complaining of asthma had attended during the preceding 15 hours. This was in contrast to an expected five to six cases and represented a 10-fold increase. Further investigation showed a similar excess of people attending with acute asthma in other accident and emergency departments across London: Newham 96; King George's, Ilford, 91; Royal London 62; Oldchurch 58; St Thomas's 44; Guy's 36; and Queen Mary's, Roehampton, 20. Several accident and emergency departments reported running out of medication, nebulisers, and mouthpieces of peak flow meters. Further ad hoc surveillance suggests that the incident spread from Bristol to Cambridge and Barnsley to Canterbury. This initial information suggests that this epidemic may be substantially larger than previously reported epidemics. ${ }^{1}$

The epidemic coincided with thunderstorms over much of Britain. In the past more circumscribed epidemic asthma has been reported after thunderstorms and is thought to be associated, at least in part, with aeroallergens such as pollen' and fungal spores. ${ }^{2}$ Other epidemics of asthma have not 